\title{
Relations among autonomic nerve dysfunction, oesophageal motility, and gastric emptying in gastro-oesophageal reflux disease
}

\author{
K M Cunningham, M Horowitz, P S Riddell, G J Maddern, J C Myers, R H Holloway, \\ J M Wishart, G G Jamieson
}

\begin{abstract}
Recent studies suggest that vagal nerve dysfunction may be important in the aetiology of gastro-oesophageal reflux disease. Delayed oesophageal transit and slowed gastric emptying occur frequently and may also be of pathogenic importance. In 48 patients with gastro-oesophageal reflux disease we studied the prevalence of and relations between autonomic nerve dysfunction (as assessed by cardiovascular reflex tests) and oesophageal transit, oesophageal motility, gastric emptying, and endoscopic grade of oesophagitis. Of the 48 patients, 21 ( $44 \%$ ) had abnormal autonomic nerve function, which was predominantly parasympathetic. Oesophageal transit was delayed in $28 \%$ of the patients and gastric emptying of the solid component of the meal was delayed in $46 \%$. Oesophageal transit was significantly $(p<0.007)$ slower in patients with abnormal autonomic nerve function. The percentage of synchronous oesophageal contractions was related to the score for autonomic nerve dysfunction $(r=0.40, p<0.05)$. There was no significant relation of autonomic nerve dysfunction to either delayed gastric emptying or endoscopic grade of oesophagitis. We conclude that in gastro-oesophageal reflux disease there is a high prevalence of parasympathetic nerve dysfunction which relates to delayed oesophageal transit and abnormal peristalsis and may therefore be of pathogenic importance.
\end{abstract}

Medicine

K M Cunningham

$M$ Horowitz

$\mathrm{J} M$ Wishart

and Surgery, University

of Adelaide

P S Riddell

G J Maddern

J C Myers

G G Jamieson

Gastroenterology Unit, Royal Adelaide Hospital, Adelaide, South

Australia, Australia 5000

R H Holloway

Correspondence to: Associate Professor M Horowitz, Department of Horowitz, Department of Medicine, Royal Adelaide Hospital, Adelaide, South
Australia.

Accepted for publication 25 March 199 patients with gastro-oesophageal reflux also have transpyloric flow are abnormal in some patients with reflux disease. ${ }^{+5}$ Such observations of abnormal oesophageal and gastric motor dys function suggest a generalised gastrointestinal delayed gastric emptying. ${ }^{10-12}$ Antral motility and smooth muscle motor abnormality in some patients with reflux disease. ${ }^{13}$

The cause of the abnormal motility in reflux disease is unknown, but evidence exists for neural dysfunction. The vagus has a major influence on oesophageal peristalsis, lower oesophageal sphincter function, and gastric motility. The hypothesis that abnormalities of vagal function contribute to the pathogenesis of reflux disease has been supported by recent observations that the gastric secretory response to insulin induced hypoglycaemia is impaired in some patients $\mathrm{s}^{14}$ and that approximately $40 \%$ of patients with reflux disease have abnormal parasympathetic cardiovascular reflexes. ${ }^{16}$ This study aimed to examine the relations between cardiovascular autonomic nerve dysfunction, oesophageal motility, oesophageal transit, and gastric emptying in gastro-oesophageal reflux disease.

\section{Methods}

\section{SUBJECTS}

We studied 48 randomly selected patients $(26$ men, 22 women) with gastro-oesophageal reflux disease, who were recruited from a cohort of subjects referred for the assessment of presumed oesophageal disease." The diagnosis of gastrooesophageal reflux was based on either erosive or ulcerative oesophagitis at endoscopy, or pathological degrees of reflux during ambulatory oesophageal pH monitoring. ${ }^{11}$ Delayed gastric or oesophageal emptying as a result of organic obstruction had been excluded previously by upper gastrointestinal endoscopy. None of the patients had diabetes mellitus, symptoms suggestive of autonomic neuropathy, or previous abdominal surgery. The median age was 52 years (range 20-81), median body weight $80 \mathrm{~kg}$ (range 48-104), and median body mass index $26 \cdot 7$ (range 19.5-36:1). Each patient underwent (a) an objective assessment of autonomic neuropathy, (b) measurement of gastric emptying, and (c) measurement of oesophageal transit. Oesophageal manometry was performed in 41 patients, and upper gastrointestinal endoscopy was performed in 44 patients.

Gastric emptying and oesophageal transit were also measured in 30 volunteers (17 men, 13 
women), median age 39 years (range 21-81), median body weight $72 \mathrm{~kg}(47-85)$, and median body mass index $22 \cdot 5(17 \cdot 7-29 \cdot 7)$. All of the volunteers were free of symptoms of gastrooesophageal reflux and had no past history of oesophageal, gastric, or duodenal disease. All the patients with gastro-oesophageal reflux and the control subjects were white. There was no significant difference in age, body weight, or body mass index between the two groups. Written informed consent was obtained from all patients and the study was approved by the Ethics Committee of the Royal Adelaide Hospital.

\section{ASSESSMENT OF AUTONOMIC NEUROPATHY}

Autonomic neuropathy was assessed by the standardised measurement of cardiovascular reflexes. ${ }^{17}$ Parasympathetic function was evaluated by the heart rate variation (R-R interval) during deep breathing at six breaths a minute ( 5 seconds in and 5 seconds out) for one minute and the immediate heart rate response to standing, in which the ratio of longest $R-R$ interval at around the 30th beat after starting to stand to the shortest R-R interval at around the 15 th beat was calculated, the so-called ' $30: 15$ ' ratio. Sympathetic function was assessed by the fall in systolic blood pressure in response to standing. The result of each of these three tests was scored as $0=$ normal, $1=$ borderline, $2=$ abnormal, according to criteria outlined by Ewing and Clarke. ${ }^{17}$ The score for parasympathetic dysfunction (maximum possible score $=4$ ) and a total score (maximum possible score $=6$ ) were derived. A total score of $\geq 2$ was taken to indicate both definite autonomic nerve damage and definite parasympathetic nerve damage.

\section{MEASUREMENT OF GASTRIC EMPTYING}

Gastric emptying of both solids and liquids was measured using a dual isotope method. ${ }^{18}$ The solid component of the meal was $100 \mathrm{~g}$ of cooked ground beef containing $1 \cdot 0-1 \cdot 5 \mathrm{mCi}$ of chicken liver labelled in vivo with technetium-99msulphur colloid. The liquid component was 150 $\mathrm{ml}$ of $10 \%$ dextrose in water labelled with $0.75-$ $1.0 \mathrm{mCi}$ of ${ }^{113 \mathrm{~m}} \mathrm{In}$-diethylenetriamenepenta-acetic acid. The test was performed at approximately 1300 when the subject had fasted after a light breakfast at 0700 hours. Each subject sat with his or her back to the scintillation camera, ate the solid meal over a five minute period, and then immediately drank the dextrose solution. Time zero was defined as the time of meal completion and each study was continued for at least two hours.

Data were corrected for patient movement, radionuclide decay, Compton scatter, and gamma ray (tissue) attenuation using methods described previously. ${ }^{18}$ The amount of the solid component of the meal remaining in the stomach at 100 minutes after the meal was completed and the time for $50 \%$ emptying of the liquid component were calculated. The $50 \%$ emptying time for the solid meal was not used because some patients did not reach this level in the study period. Gastric emptying was classified as delayed when values were greater than the whole range of values in the control subjects.

\section{MEASUREMENT OF OESOPHAGEAL TRANSIT}

Oesophageal transit of a solid bolus was measured immediately before gastric emptying as described previously. ${ }^{19}{ }^{20}$ After swallowing $5 \mathrm{ml}$ of water as a lubricant, the seated subject swallowed a $10 \mathrm{~g}$ bolus of the solid meal and was then asked to swallow on command every 15 seconds. Cricoid movement was monitored to ensure that no additional swallows were taken, and the visual display of the gamma camera was used to confirm that the bolus had entered the oesophagus after the first swallow, using the level of the cricoid cartilage as a marker. Monitoring was continued until the bolus was seen to enter the stomach, or until 20 swallows (=300 s) had been performed. Analysis was performed using computer-drawn regions of interest corresponding to the oesophagus (cricoid to gastro-oesophageal junction) and the stomach, and the time for $95 \%$ of the radioactivity to enter the stomach was calculated. Oesophageal transit was classified as delayed when values were greater than the control range. ${ }^{20}$

MEASUREMENT OF OESOPHAGEAL MOTILITY

Oesophageal manometry was performed in 41 of the patients and technically satisfactory recordings were obtained for 36. A multilumen assembly that was perfused by a low compliance capillary infusion system was used. A sleeve sensor monitored lower oesophageal sphincter pressure. ${ }^{21}$ Side holes monitored pressure in the gastric fundus and in the oesophageal body at 2 , 7,12 , and $17 \mathrm{~cm}$ above the lower oesophageal sphincter. Each lumen was perfused at $0.5 \mathrm{ml} /$ min and sudden occlusion of the side holes resulted in a pressure rise of $>200 \mathrm{~mm} \mathrm{Hg} / \mathrm{s}$. Basal lower oesophageal sphincter pressure was recorded for five minutes, and oesophageal peristalsis was assessed in response to 10 water swallows ( $5 \mathrm{ml}$ bolus). Basal end-expiratory sphincter pressure was referenced to intragastric pressure and determined for each of the five minutes by taking a one minute visual mean of the tracing and deriving a mean value for the five minutes. Contraction amplitudes for peristalsis in response to water swallows were calculated as the mean amplitude for the three distal oesophageal recording sites. Oesophageal motor

TABLE I Results of three cardiovascular reflex tests in 48 patients with oesophageal reflux

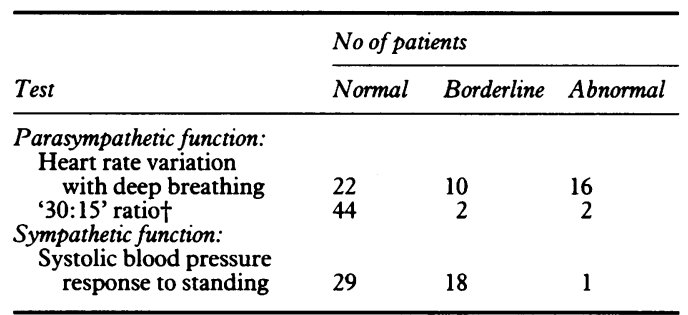

^Classification of each test according criteria of Ewing and Clarke.

† Ratio of longest $R-R$ interval (heart rate variation) at 30 th beat after starting to stand to the shortest $R-R$ interval at the 15 th beat. 

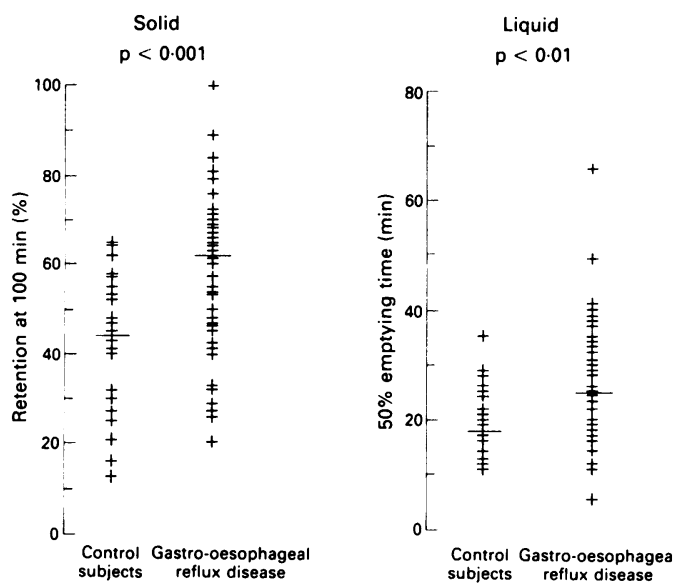

Figure 1: Gastric emptying of the solid and liquid components of the meal in 30 control subjects and 48 patients with gastrooesophageal reflux disease. Horizontal lines represent the median values.

responses to water swallows were classified as either successful or failed peristalsis. Peristalsis was judged to have failed if either a pressure wave $>10 \mathrm{~mm} \mathrm{Hg}$ failed to traverse each of the oesophageal recording points or synchronous contractions occurred at two or more of the distal three recording sites. ${ }^{22}$

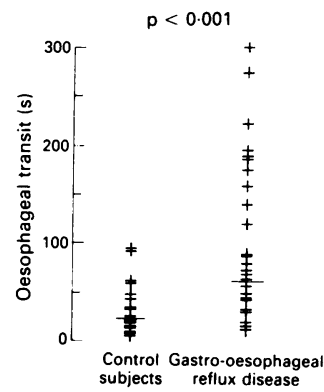

Figure 2: Oesophageal transit of a solid bolus in 30 control subjects and 47 patients with gastrooesophageal reflux disease. Horizontal lines represent the median values.

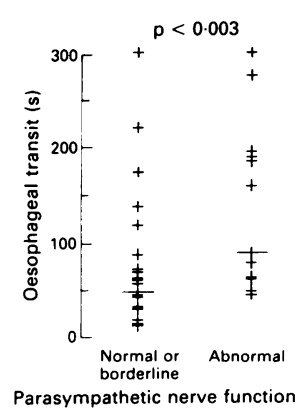

Figure 3: Oesophageal transit of a solid bolus in 47 patients with gastrooesophageal reflux disease with abnormal (score $\geqslant 2$ ) and either normal or borderline (score $<2$ ) parasympathetic cardiovascular autonomic function. Horizontal lines represent the median values.
UPPER GASTROINTESTINAL ENDOSCOPY

The severity of macroscopic oesophagitis was graded as $\mathbf{0}=$ normal, $1=$ mucosal erythema without macroscopic mucosal lesions, 2 =erosions, $3=$ confluent erosions, ulceration, or Barrett's oesophagus. ${ }^{20}$

\section{STATISTICAL ANALYSIS} test (unpaired data) and linear regression analysis and are expressed as median values and ranges unless otherwise stated.

\section{Results}

\section{AUTONOMIC NERVE FUNCTION}

Abnormalities of cardiovascular reflexes, breathing, occurred frequently (Table I). Twenty one patients $(44 \%)$ had definite evidence of autonomic neuropathy (total score $\geqslant 2$ ) and 30 $(63 \%)$ had a score of 1 or more. The heart rate response to deep breathing was abnormal in 16 (33\%) patients. The total score for parasympathetic function was abnormal in $17(35 \%)$ patients and $26(54 \%)$ had a score of 1 or more. The total score for autonomic nerve dysfunction $(\mathrm{r}=0.58, \mathrm{p}<0.001)$ and the score for parasympathetic dysfunction $(\mathrm{r}=0.56, \mathrm{p}<0.001)$ correlated significantly with age. Correspondingly, the median age of patients with an abnormal total score $(\geqslant 2)$ was higher than that in patients with a score of either 0 or 1 (median (range) 61 years $(40-81$ years) $v 48$ years $(19-66)$, $\mathrm{p}<0.002$ ). There was no significant difference in body weight or body mass index in patients with normal autonomic nerve function when compared with those in the remainder of the group.
Data were evaluated using the Mann-Whitney U particularly the heart rate response to deep
GASTRIC EMPTYING

The percentage of the solid meal remaining in the stomach at 100 minutes was greater than the upper limit of the control range in $22(46 \%)$ of the 48 patients, and the $50 \%$ emptying time for the liquid was greater than the upper limit of the control range in eight patients (17\%) (Fig 1). Solid and liquid gastric emptying correlated significantly in the patients $(r=0.34, p<0.05)$. Gastric emptying was not significantly related to age, body weight, or body mass index.

\section{OESOPHAGEAL TRANSIT}

In all subjects the bolus of food entered the oesophagus after the first swallow and no food was retained in the oesophagus after the liquid component of the meal was consumed. The data from the oesophageal transit test were lost for one subject due to a computer malfunction. Patients with reflux disease had significantly delayed $(p<0.001)$ oesophageal transit compared with that in the control subjects, and in 13 of the 47 patients ( $28 \%$ ) oesophageal transit was greater than the upper limit of the control range (Fig 2). There was no significant relation between oesophageal transit and body weight, body mass index, or age. There was no significant difference in the age of subjects with delayed oesophageal transit, when compared with that of the remainder of the group (median (range) 50 years $(24-81) v 52$ years $(19-72))$

\section{OESOPHAGEAL MOTILITY}

Pooled values for oesophageal motility are summarised in Table II. The percentage of synchronous contractions was weakly related to age $(r=0.36 ; p<0.05)$, but otherwise there were no significant correlations between oesophageal motor function and age, body weight, or body mass index.

\section{ENDOSCOPIC GRADE OF OESOPHAGITIS}

No patient was classified as grade 0 oesophagitis; 23 patients were classified as grade $1 ; 16$ patients as grade 2; and five patients as grade 3 . There was no significant correlation between the endoscopic grading and age, body weight, or body mass index.

\section{RELATIONS BETWEEN AUTONOMIC NERVE} FUNCTION AND OESOPHAGEAL TRANSIT, OESOPHAGEAL MOTILITY, ENDOSCOPIC GRADE OF OESOPHAGITIS, AND GASTRIC EMPTYING

Values for oesophageal transit, oesophageal motility, grade of oesophagitis, and gastric emptying in patients with normal and abnormal parasympathetic nerve function are given in Table II. Oesophageal transit was significantly $(\mathrm{p}<0.003)$ slower in patients with abnormal parasympathetic nerve function (Fig 3 ) and was also slower in patients with an abnormal total score compared with the remainder of the group (median (range) $90 \mathrm{~s}(42-300) v 48 \mathrm{~s}(12-300)$, $\mathrm{p}<0.007)$. Multiple regression analysis (Table III) suggested that autonomic neuropathy may be more important than age alone in determining 
TABLE II Oesophageal transit, grade of oesophagitis, and oesophageal motility in patients with normal and abnormal parasympathetic nerve function (median (range))

\begin{tabular}{|c|c|c|c|}
\hline \multirow[b]{2}{*}{ Parameter } & \multicolumn{3}{|c|}{ Parasympathetic nerve function } \\
\hline & Normal & Abnormal & Significance \\
\hline Oesophageal transit (s) & $\begin{array}{l}48(12-300) \\
(n=30)\end{array}$ & $\begin{array}{l}90(44-300) \\
(n=17)\end{array}$ & $<0.01$ \\
\hline $\begin{array}{l}\text { Endoscopic grade of oesophagitis } \\
\text { Oesophageal motility: }\end{array}$ & $1(1-3)$ & $2(1-2)$ & NS \\
\hline $\begin{array}{l}\text { Basal lower oesophageal sphincter } \\
\text { pressure (mm Hg) } \\
\text { Peristalsis: }\end{array}$ & $12 \cdot 7(3 \cdot 5-38)$ & $11 \cdot 0(0-45)$ & NS \\
\hline $\begin{array}{l}\text { Success (\%) } \\
\text { Mean amplitude (mm Hg) } \\
\text { Synchronous waves (\%) } \\
\text { Hypotensive (\%) }\end{array}$ & $\begin{array}{l}100(30-100) \\
64 \cdot 4(27 \cdot 4-171) \\
0(0-28 \cdot 6) \\
0(0-70) \\
(\mathrm{n}=22)\end{array}$ & $\begin{array}{l}85 \cdot 4(50-100) \\
55 \cdot 1(29 \cdot 6-98 \cdot 3) \\
4 \cdot 5(0-50) \\
0(0-28 \cdot 6) \\
(n=14)\end{array}$ & $\begin{array}{l}\text { NS } \\
\text { NS } \\
\text { NS } \\
\text { NS }\end{array}$ \\
\hline $\begin{array}{l}\text { Gastric emptying: } \\
\text { Retention of solid at } 100 \mathrm{~min}(\%) \\
\text { Liquid } 50 \% \text { emptying time (min) }\end{array}$ & $\begin{array}{l}60(20-100) \\
24(5-66) \\
(n=31)\end{array}$ & $\begin{array}{l}66(20-89) \\
25(12-49) \\
(n=17)\end{array}$ & $\begin{array}{l}\text { NS } \\
\text { NS }\end{array}$ \\
\hline
\end{tabular}

oesophageal transit, although the relation with autonomic neuropathy was not significant. There were non-significant trends for an increased percentage of synchronous waves $(p=$ $0.09)$ and decreased peristaltic amplitude $(p=$ 0.15 ) in the group with abnormal parasympathetic function, and a weak but significant relation between the total score for autonomic nerve function and the percentage of synchronous waves $(r=0.40, p<0.05)$, but not mean peristaltic amplitude $(\mathrm{r}=-0 \cdot 21)$.

There were no significant differences in gastric emptying or endoscopic grade of oesophagitis between the two groups. There were no significant correlations between oesophageal transit and oesophageal motility, endoscopic grade of oesophagitis, or gastric emptying nor between the endoscopic grade of oesophagitis and gastric emptying.

\section{Discussion}

Our study confirms previous reports ${ }^{14-16}$ of a high prevalence of abnormal parasympathetic function in patients with gastro-oesophageal reflux disease. As reported by Chakraborty et $a l,{ }^{16}$ the patients with autonomic neuropathy were older than those with no autonomic neuropathy, but as their results were outside the normal range for subjects of any age $^{17}$ these findings cannot be interpreted as reflecting an effect of aging on autonomic nerve function. The high prevalence of parasympathetic cardiovascular dysfunction, which was unrelated to the grade of oesophagitis, indicates that the vagal nerve impairment in gastro-oesophageal reflux disease is not a secondary phenomenon, contrary to what has been suggested. ${ }^{23}$

We have shown for the first time a relation

TABLE III Multiple regression of oesophageal transit on age and score for autonomic nerve dysfunction in 47 patients with gastro-oesophageal reflux disease

\begin{tabular}{lccll} 
& Slope & $\begin{array}{c}\text { Standard } \\
\text { error }\end{array}$ & $t$ & Probability \\
\hline $\begin{array}{l}\text { Age (years) } \\
\begin{array}{c}\text { Autonomic } \\
\text { neuropathy } \\
\text { score }\end{array}\end{array}$ & 0.06 & 0.95 & 0.06 & 0.95 \\
$\begin{array}{l}\text { Intercept } \\
27.53\end{array}$ & 26.87 & & & \\
\hline
\end{tabular}

Multiple $\mathrm{r}=0.31 ; \mathrm{p}<0.05$. between vagal neuropathy and both delayed oesophageal transit and abnormal peristalsis in gastro-oesophageal reflux disease. Measurement of the transit of radioisotopically labelled boluses is a sensitive test of oesophageal peristaltic function. ${ }^{24} 25$ A substantial percentage of patients with gastro-oesophageal reflux disease have delayed transit of solid or liquid boluses ${ }^{6-8}$ that seems to involve all segments of the oesophagus. ${ }^{26}$ Delayed transit is most likely to be related to the impaired oesophageal peristaltic function that occurs in up to $50 \%$ of patients with reflux disease. ${ }^{39}$ Although we were unable to show a significant correlation between oesophageal motility and transit, this may have resulted from the two measurements having been done on separate occasions, since concurrent measurements with liquid have shown a good correlation between the two measurements. ${ }^{27}$

It has been suggested that peristaltic dysfunction in gastro-oesophageal reflux disease is secondary to acid reflux damage to the oesophageal wall ${ }^{20}$ or the adjacent vagus nerves, ${ }^{23}$ or both. Others have argued that there is a primary disorder of oesophageal motility in gastro-oesophageal reflux. ${ }^{262829}$ Our data suggest that in a subset of patients impaired peristalsis is due to vagal neuropathy that is not caused by oesophagitis. Like Chakraborty et al,,$^{16}$ we found no difference in the grade of oesophagitis, lower oesophageal sphincter pressure, or peristaltic amplitude between patients with and without autonomic neuropathy. We found, however, that abnormal autonomic nerve function was weakly related to failed peristalsis associated with an increased number of synchronous contractions. The latter was not examined in the previous study. ${ }^{16}$

Our study has confirmed that delayed gastric emptying occurs in about $50 \%$ of patients with reflux disease and is not related to delayed oesophageal transit. ${ }^{10-12}$ The absence of a significant correlation between gastric emptying and autonomic nerve function suggests that this abnormality is not caused by a vagal neuropathy. The importance of delayed gastric emptying to the pathogenesis of gastro-oesophageal reflux disease remains uncertain. ${ }^{30}$ Delayed gastric emptying may be expected to increase the amount of refluxate and, by effects on gastric distension, to increase the frequency of transient lower oesophageal sphincter relaxations. ${ }^{29}$ Delayed gastric emptying has been suggested as a rationale for the use of prokinetic drugs, such as metoclopramide, in the treatment of gastrooesophageal reflux..$^{31}$ It is of interest that antireflux surgery with fundoplication enhances gastric empting ${ }^{32}$ and when antireflux procedures fail there is a strong association with delayed gastric emptying of solids and liquids. ${ }^{33}$

We have confirmed that in gastro-oesophageal reflux disease there is a high prevalence of abnormal parasympathetic nerve function and shown for the first time that this relates to delayed oesophageal transit and abnormal peristalsis.

We thank Mrs M Marucci for typing this manuscript. KC was supported by a research fellowship provided by the Royal Adelaide Hospital. The project was supported by a grant from the National Health and Medical Research Council of Australia. 
1 Dent J. Recent views on the pathogenesis of gastrooesophageal reflux disease. Baillière's clinical gastroenterology 1987; 1 : reflux dise $727-45$.

2 Holloway RH, Dent J. Pathophysiology of gastrooesophageal reflux disease: lower esophageal dysfunction in gastroesophageal reflux disease. Gastroenterol Clin North Am 1990 19:517-36.

3 Kahrilas PJ, Dodds WJ, Hogan WJ, Kern M, Arndorfer RC, Reece A. Esophageal peristaltic dysfunction in peptic esophagitis. Gastroenterology 1986; 91: 897-904.

4 Behar J, Ramsby G. Gastric emptying and antral motility in reflux esophagitis. Gastroenterology 1978; 74: 253-6.

5 King PM, Pryde A, Heading RC. Transpyloric fluid movements and antroduodenal motility in patients with gastrooesophageal reflux. Gut 1987; 28 : 545-8.

6 Russell COH, Pope CE II, Gannam RM, et al. Does surgery correct esophageal motor dysfunction in gastroesophageal correct esophageal motor dysfunction
reflux. Ann Surg 1981; 194: 290-6.

7 Maddern GJ, Jamieson GG. Oesophageal emptying in patients with gastro-oesophageal reflux. Br $\mathcal{F}$ Surg 1986; 73: 615-7.

8 Roland J, Peters O, Piepsz A, Devis G, Jonckheer M, Ham HR. Evaluation of oesophageal transit in patients with mino peptic oesophagitis. Nucl Med Commun 1989; 10: 161-5.

9 Kahrilas PJ, Dodds WJ, Hogan WJ. Effect of peristaltic dysfunction on esophageal volume clearance. Gastro enterology 1988; 94: 73-80.

10 McCallum RW, Berkowitz DM, Lerner E. Gastric emptying in patients with gastroesophageal reflux. Gastroenterology 1981; 80: 285-91.

11 Maddern GJ, Chatterton BE, Collins PJ, Horowitz M, Shearman DJC, Jamieson GG. Solid and liquid gastric emptying in patients with gastro-oesophageal reflux. $\mathrm{Br} \mathcal{J}$ Surg 1985; 72: 344-7.

12 Collins BJ, McFarland RJ, O'Hare MMT, Shaw C, Buchanan KD. Gastric emptying of a solid-liquid meal and gastrointestinal hormone responses in patients with erosive oesophagitis. Digestion 1986; 33: 61-8.

13 Hillemeier AC, Grill BB, McCallum R, Gryboski J Esophageal and gastric motor abnormalities in gastroesophageal reflux during infancy. Gastroenterology 1983; 84: $741-6$.

14 Heatley RV, Collins RJ, James PD, Atkinson M. Vaga function in relation to gastro-oesophageal reflux and associated motility changes. BMF $1980 ; 280 ; 755-7$.

15 Ogilvie AL, James PD. Impairment of vagal function in reflux oesophagitis. Qf Med 1985; 54: 61-74.

16 Chakraborty TK, Ogilvie AL, Heading RC, Ewing DJ. Abnormal cardiovascular reflexes in patients with gastroAbnormal cardiovascular reflexes in pat

17 Ewing DJ, Clarke BF. Diagnosis and management of diabetic autonomic neuropathy. $B M \mathcal{F}$ 1982; 285: 916-8.
18 Collins PJ, Horowitz M, Cook DJ, Harding PE, Shearman DJC. Gastric emptying in normal subjects - a reproducible technique using a single scintillation camera and computer system. Gut 1983; 24: 1117-25.

19 Horowitz M, Harding PE, Maddox A, Maddern GJ, Collins PJ, Chatterton BE, et al. Gastric and oesophageal emptying in insulin-dependent diabetes mellitus. $\mathcal{F}$ Gastroentero Hepatol 1986; 1: 97-113.

20 Maddern GJ, Slavotinek JP, Collins PJ, Jamieson GG. The effect of posture and $\mathrm{pH}$ on solid and liquid oesophagea emptying. Clin Physiol 1985; 5: 425-32.

21 Dent J. A new technique for continuous sphincter pressure measurement. Gastroenterology 1976; 71: 263-7.

22 Dent J, Holloway R, Toouli J, Dodds WJ. Mechanisms of lower oesophageal sphincter incompetence in patients with symptomatic gastro-oesophageal reflux. Gut 1988; 29: $1020-8$.

23 Little AG, DeMeester TR, Kirchner PT, O'Sullivan GC Skinner DB. Pathogenesis of oesophagitis in patients with gastroesophageal reflux. Surgery 1980; 88: 101-7.

24 Blackwell JN, Castell DO, Oesophageal motility: recent advances and implications. Clin Sci 1984; 67: 145-51.

25 Holloway RH, Lange RC, Plankey MW, McCallum RW Detection of esophageal motor disorders by radionuclide transit studies. A reappraisal. Dig Dis Sci 1989; 34: 905 -12 .

26 Eriksen CA, Sadek SA, Cranford C, Sutton D, Kennedy N, Cuschieri A. Reflux oesophagitis and oesophageal transit evidence for a primary oesophageal motor disorder. Gut 1988; 29: 448-52.

27 Richter JE, Blackwell JN, Wu WC, Johns DN, Cowan RJ, Castell DO. Relationship of radionuclide liquid bolus transport and esophageal manometry. F Lab Clin Med 1987; 109: 217-24.

28 Gill RC, Bowes KL, Murphy PD, Kingma YJ. Esophageal motor abnormalities in gastroesophageal reflux and the effects of fundoplication. Gastroenterology 1986; 91: 364-9.

29 Holloway RH, Hongo M, Berger M, McCallum RW. Gastric distension a mechanism for post prandial gastroesophagea reflux. Gastroenterology 1985; 89; 779-84.

30 Dubois A. Clinical relevance of gastroduodenal dysfunction in reflux oesophagitus. f Clin Gastroenterol 1986; 8 (suppl 1): 17-25.

31 Fink SM, Lange RC, McCallum RW. Effect of metoclopramide on normal and delayed gastric emptying in gastropramide on normal and delayed gastric emptying in gastro-

32 Maddern GJ, Jamieson GG. Fundoplication enhances gastric Maddern GJ, Jamieson GG. Fundoplica

33 Maddern GJ, Jamieson GG, Chatterton BE, Collins PJ. Is there an association between failed antireflux procedures and delayed gastric emptying? Ann Surg 1985; 202: 162-5. 